ARTICLE

https://doi.org/10.1038/s41467-019-09573-4

\title{
Free radical sensors based on inner-cutting graphene field-effect transistors
}

\author{
Zhen Wang $1,2,3$, Kongyang Yi (10 1,2,3, Qiuyuan Lin ${ }^{4}$, Lei Yang ${ }^{1,2,3}$, Xiaosong Chen ${ }^{1,2,3}$, Hui Chen ${ }^{4}$, Yunqi Liu ${ }^{3}$ \&
} Dacheng Wei (1) $1,2,3$

Due to ultra-high reactivity, direct determination of free radicals, especially hydroxyl radical $(\bullet \mathrm{OH})$ with ultra-short lifetime, by field-effect transistor (FET) sensors remains a challenge, which hampers evaluating the role that free radical plays in physiological and pathological processes. Here, we develop a $\cdot \mathrm{OH}$ FET sensor with a graphene channel functionalized by metal ion indicators. At the electrolyte/graphene interface, highly reactive $\cdot \mathrm{OH}$ cuts the cysteamine to release the metal ions, resulting in surface charge de-doping and a current response. By this inner-cutting strategy, the $\cdot \mathrm{OH}$ is selectively detected with a concentration down to $10^{-9} \mathrm{M}$. Quantitative metal ion doping enables modulation of the device sensitivity and a quasi-quantitative detection of $\cdot \mathrm{OH}$ generated in aqueous solution or from living cells. Owing to its high sensitivity, selectivity, real-time label-free response, capability for quasi-quantitative detection and user-friendly portable feature, it is valuable in biological research, human health, environmental monitoring, etc.

\footnotetext{
${ }^{1}$ State Key Laboratory of Molecular Engineering of Polymers, Fudan University, 200433 Shanghai, China. ${ }^{2}$ Department of Macromolecular Science, Fudan University, 200433 Shanghai, China. ${ }^{3}$ Institute of Molecular Materials and Devices, Fudan University, 200433 Shanghai, China. ${ }^{4}$ Department of Chemistry, Fudan University, 200433 Shanghai, China. These authors contributed equally: Zhen Wang, Kongyang Yi. Correspondence and requests for materials should be addressed to D.W. (email: weidc@fudan.edu.cn)
} 
D etection of the free radical is of great importance for human health, as the free radical is generally believed to play important roles in the pathogenesis of various human diseases ${ }^{1}$. For instance, overproduced reactive oxygen species (ROS) cause oxidative stress through the oxidation of biomolecules, such as lipids, proteins, and DNA, in cells and tissues $^{1,2}$. Among them, hydroxyl radical $(\bullet \mathrm{OH})$, as one of the most reactive chemical species known, induces large aggression to human health due to its ultra-high reactivity with various biological species compared with other $\mathrm{ROS}^{3-5}$. The $\cdot \mathrm{OH}$ can damage the bases of DNA and mediate redox alteration of cellmembrane $\mathrm{Ca}^{2+}$ channels. Therefore, the fast and real-time monitoring strategies for physiologically important free radicals, especially the $\bullet \mathrm{OH}$, is of great significance. Till now, analytical methods are still the bottleneck for progress in understanding physiological and pathological events such as aging, cancer, ischemia/reperfusion injury, traumatic brain injury, etc. ${ }^{1,6,7}$. In order to understand the role that free radical plays in biological and pathological events, much attention has been paid on monitoring the free radicals in living systems. Traditionally, the free radical is detected by electron spin resonance (ESR) spectroscopy $^{8}$, fluorescence spectroscopy ${ }^{9-11}$, chromatography ${ }^{12,13}$, and electrochemical approaches ${ }^{14}$. However, these techniques suffer from some of the disadvantages such as costly instrumentation, low throughput, complicated sample preparation, need for welltrained operators, or lack of portability. Moreover, these techniques normally require spin traps or fluorescent probes, which introduce additional contaminations that are involved in the detection system and interfere with the desired signals ${ }^{8-14}$. The spin traps or fluorescent probes determine the detection limit and selectivity. In some cases, the detection limit of $\bullet \mathrm{OH}$ is only $10^{-6}$ $\mathrm{M}$ (fluorescence) ${ }^{9,11}$, while $\mathrm{ROS}$ such as $\bullet \mathrm{O}_{2}{ }^{-}$and $\bullet \mathrm{HO}_{2}$ can also induce a response in the fluorescence or ESR signal ${ }^{10,15}$. Therefore, it is still a challenge to real-time monitor the free radicals with high sensitivity and selectivity by a low-cost, portable, and user-friendly analytical platform.

As a promising detection technique, field-effect transistor (FET)-based sensor works by transducing and monitoring the absorbate-induced perturbations into the conductance change in the channel materials, typically in terms of the source-drain current $^{16,17}$. The channel material with high surface-to-volume ratio is favorable generally since it implies higher adsorption site density available ${ }^{18}$. Owing to its high carrier mobility and atomic thickness, graphene bears ultra-high sensitivity to electrical perturbations from the external environment ${ }^{17,19-22}$, which has been integrated into FET sensors with advantages such as labelfree detection, high stability, flexibility, fast response, biological compatibility, and user-friendship ${ }^{23}$, compared with other detection techniques. In a graphene-based FET sensor, the graphene is normally surface functionalized, and the specific interaction between the functional group and the analyte allows the selective detection of the $\mathrm{pH}^{24}, \mathrm{DNA}^{25}, \mathrm{RNA}^{26}$, living cells ${ }^{27,28}$, $\operatorname{gas}^{29}$, metal ions ${ }^{30-32}$, etc. Although the free radical has a strong doping effect to graphene ${ }^{33,34}$, it is still challenging to directly monitor the free radical in the aqueous environment by the FET sensors. One pioneering work $^{35}$ develops a poly(3-hexylthiophene) FET sensor functionalized with rutin. The oxidation of rutin by superoxide $\left(\cdot \mathrm{O}_{2}{ }^{-}\right)$induces current perturbations and enables the detection of $\cdot \mathrm{O}_{2}{ }^{-}$. However, compared with $\cdot \mathrm{O}_{2}{ }^{-}$or other ROS, the highly reactive $\bullet \mathrm{OH}$ has ultra-short lifetime. The lifetime of $\bullet \mathrm{OH}$ is around $3 \times 10^{-6} \mathrm{~s}^{36}, 6$ orders of magnitude shorter than that of $\bullet \mathrm{O}_{2}^{-}(\sim 1 \mathrm{~s})^{37}$. Considering the ultra-short lifetime and the relatively low rate constant of the oxidation reaction (i.e., $1.5 \times 10^{6} \mathrm{M}^{-1} \mathrm{~s}^{-1}$ for the reaction between $\cdot \mathrm{O}_{2}{ }^{-}$ and rutin $)^{38}$, the $\bullet \mathrm{OH}$ is easy to convert to $\mathrm{H}_{2} \mathrm{O}_{2}$ or other ROS without reaction with the functional groups. Till now, a FET sensor that can monitor highly reactive free radicals like $\bullet \mathrm{OH}$ is still absent. Moreover, besides the $\mathrm{pH}$ value, quantitative analysis of the chemicals is difficult for a FET sensor, hampering its practical applications, especially in the bio-system.

Herein we develop a FET sensor that can selectively detect highly reactive free radicals. The FET sensor has a graphene channel functionalized with metal ion indicators via cysteamine as the inner connector. Owing to the ultra-fast reaction between - $\mathrm{OH}$ and thiol derivatives (rate constant: $\sim 10^{10} \mathrm{M}^{-1} \mathrm{~s}^{-1}$ )[5], the cysteamine can be selectively cut by the $\bullet \mathrm{OH}$ despite of its ultrashort lifetime ${ }^{39-41}$. At the electrolyte/graphene interface, metal ions are released from graphene, leading to a surface charge dedoping and a current response in the channel. Thus, by monitoring the current perturbations induced by the metal ions, the inner-cutting strategy enables indirect detection of $\bullet \mathrm{OH}$ with a concentration down to $10^{-9} \mathrm{M}$. The label-free real-time detection has high selectivity to $\bullet \mathrm{OH}$ over metal ions or other ROS interferents. The sensitivity can be easily tuned by modifying the graphene channel with different amounts of metal ions, and then quasi-quantitative detection of $\bullet \mathrm{OH}$ is realized when measuring the sample by using FET sensors with different sensitivities. As an application, the FET sensors were used in quasi-quantitative detection of $\bullet \mathrm{OH}$ generated from Hela cells, showing great potential of the inner-cutting strategy for practical applications in monitoring free radicals or other analytes with ultra-high reactivity and ultra-short lifetime.

\section{Results}

Device fabrication and the $\bullet \mathrm{OH}$ detection. The fabrication procedure of the FET sensor is schematically shown in Fig. 1a. Briefly, a monolayer graphene produced by chemical vapor deposition (CVD; Supplementary Note 1) is transferred onto a $\mathrm{SiO}_{2} / \mathrm{Si}$ substrate, where graphene acts as the sensing channel, $\mathrm{SiO}_{2}$ as the gate dielectric, and $\mathrm{Si}$ as the back gate. Raman spectrum (Fig. $1 \mathrm{~b}$ ) shows a tiny $D$ peak, a strong and sharp $2 D$ peak compared with the $G$ peak, indicating the high quality and the monolayer nature of the graphene. And then $\mathrm{Cr} / \mathrm{Au}(5 / 50 \mathrm{~nm}$ thickness) is patterned on graphene by photolithography as the electrodes. Au nanoparticles (NPs) are deposited onto the graphene channel by vacuum evaporation and thermal annealing (step i). The resulting channel is denoted as graphene/Au. Fieldemission scanning electron microscopic (FESEM) and transmission electron microscopic (TEM) images reveal that the $\mathrm{Au}$ NPs are uniformly distributed on the graphene surface without agglomeration (Fig. 1c, Supplementary Fig. 1). Atomic force microscopic (AFM) images show that the height of the Au NPs is around $4 \mathrm{~nm}$ (Supplementary Fig. 2a). The van-der-Waals binding between $\mathrm{Au}$ NPs and graphene is strong enough to retain $\mathrm{Au}$ NPs in place even after several cycles of washing and drying. After that, the device is submerged in $10^{-3} \mathrm{M}$ cysteamine solution in order to assemble a monolayer of cysteamine on Au NPs (graphene/Au/Cys) through $\mathrm{Au}-\mathrm{S}$ bonds (step ii). Finally, protoporphyrin IX (PP) is immobilized on the cysteamine (graphene/ $\mathrm{Au} / \mathrm{Cys}-\mathrm{PP}$ ) (step iii). The corresponding AFM image shows that the height of the Au NPs increases to around $6 \mathrm{~nm}$ (Supplementary Fig. 2b), indicating the successful modification of Cys-PP onto Au NPs. To characterize the chemical structure, the sample is measured by X-ray photoelectron spectroscopy (XPS, Fig. 1d-f) after each step. Au $4 f_{7 / 2}$ and $\mathrm{Au} 4 f_{5 / 2}$ peaks located at about 82.7 and $86.4 \mathrm{eV}$ appear after step i, which are ascribed to Au NPs on the graphene. S $2 p(164.2 \mathrm{eV})$ and $\mathrm{N} 1 s(400.4 \mathrm{eV})$ peaks appear after step ii, indicating immobilization of cysteamine onto graphene/Au. A slight increase of $\mathrm{N} 1 s$ peak and decrease of S $2 p$ are observed after step iii. The result implies the successful assembly of PP, since PP contains high proportion of $\mathrm{N}$ without 
a

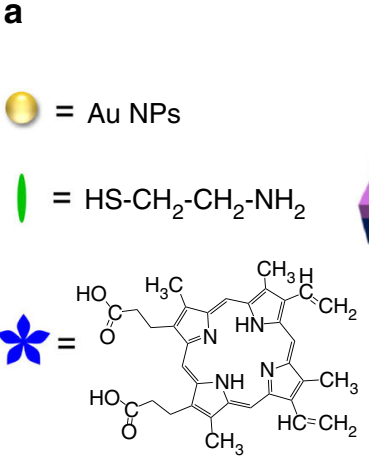

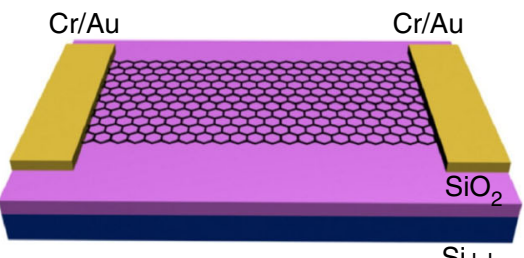

Graphene

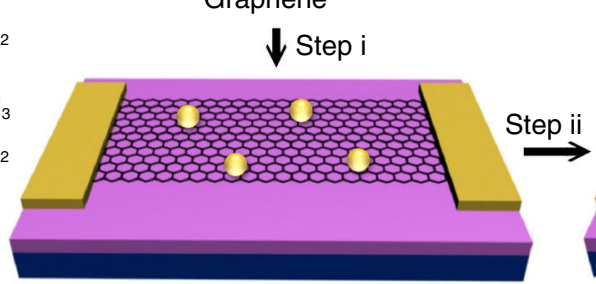

Graphene/Au

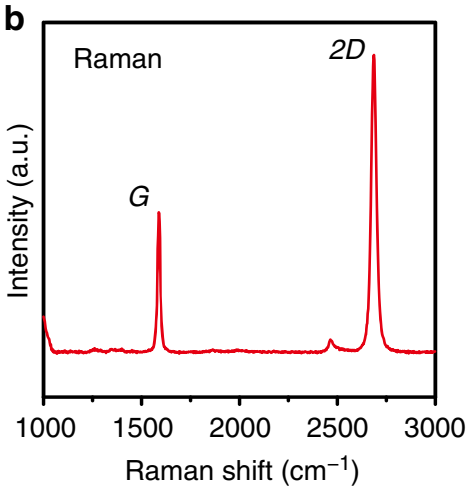

C

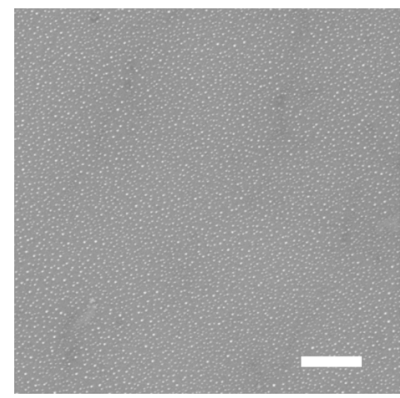

d
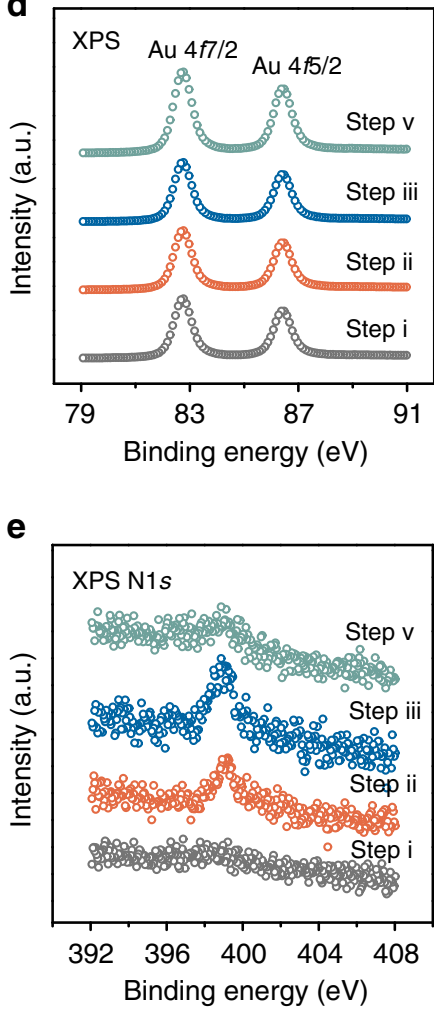

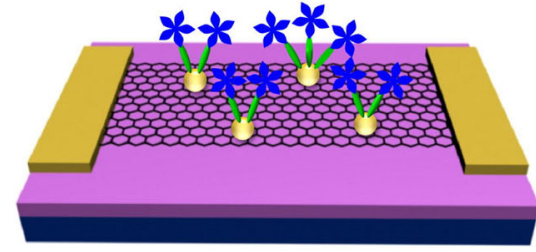

Graphene/Au/Syc-PP

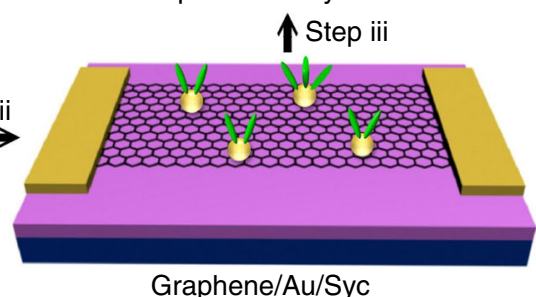

Graphene/Au/Syc

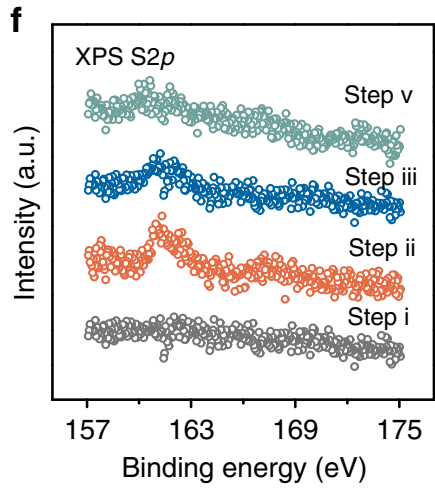

g

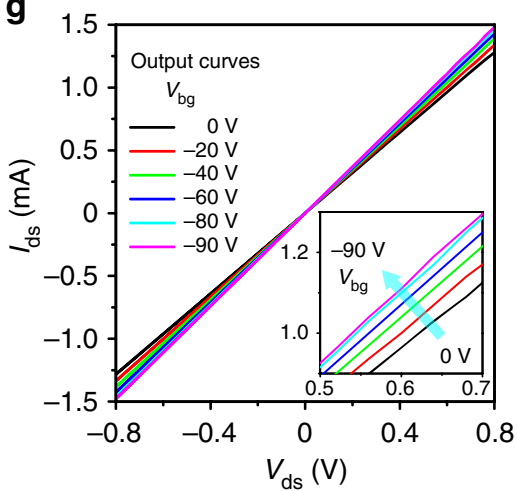

Fig. 1 Fabrication and characterization of a field-effect transistor (FET) sensor. a Schematic diagram of the device fabrication process. b Raman spectrum of a graphene film. c Field-emission scanning electron microscope images of the graphene film decorated with Au nanoparticles (step i). $\mathbf{d}$-f $\mathbf{X}$-ray photoelectron spectroscopic spectra of $A u 4 f_{7 / 2}$ and $A u 4 f_{5 / 2}, S 2 p$, and N 1s for (step i) graphene/Au, (step ii) graphene/Au/Cys, (step iii) graphene/Au/ Cys-PP, and (step v) graphene/Au/Cys-PP-Cd ${ }^{2+}$ after reaction with $\bullet \mathrm{OH}$. g Output characteristics of a graphene/Au/Cys-PP FET sensor $\left(V_{\mathrm{bg}}\right.$ varies from 0 to $-90 \mathrm{~V}$ ). The scale bar in $\mathbf{c}$ is $200 \mathrm{~nm}$

S. In contrast, Cys-PP cannot be directly linked to graphene surface as no $\mathrm{N} 1 s$ or S $2 p$ peaks appear on bare graphene after step iii (Supplementary Fig. 3). Moreover, an obvious peak at 403 $\mathrm{nm}$ appears in ultraviolet-visible (UV-vis) absorption spectrum after step iii, confirming that the PP is successfully modified on the channel (Supplementary Fig. 4).

To obtain a solution-based FET sensor (Figs. 1g and 2a, b), a chamber is fabricated on the channel, which is employed for all solution-based measurements. The electrodes are located beside the chamber with channel length around $8 \mathrm{~mm}$. After dipping in $1 \times$ $10^{-5} \mathrm{M} \mathrm{Cd}^{2+}$ aqueous solution, $\mathrm{Cd}^{2+}$ ions are bound to the channel surface to charge-dope graphene (Fig. 2c) (graphene/Au/ Cys-PP-Cd $\left.{ }^{2+}\right)^{42,43}$. In the process, the drain-source current $\left(I_{\mathrm{ds}}\right)$ rapidly decreases upon successive addition of $\mathrm{Cd}^{2+}$. After coordination with $\mathrm{Cd}^{2+}$ (step iv), the $I_{\mathrm{ds}}$ of the graphene/Au/ Cys-PP-Cd ${ }^{2+}$ channel (Fig. 2d) shows a rapid response upon exposure to $1 \times 10^{-4} \mathrm{M} \bullet \mathrm{OH}$ within $2 \mathrm{~s}$ (step v), thus the graphene/ $\mathrm{Au} / \mathrm{Cys}-\mathrm{PP}-\mathrm{Cd}^{2+}$ FET works as a real-time label-free $\bullet \mathrm{OH}$ sensor. The current changes (Supplementary Fig. 5) are detectable even when the concentration of $\bullet \mathrm{OH}$ decreases to $10^{-7} \mathrm{M}$.

The complexity of biological systems presents a great challenge in selective detection of $\bullet \mathrm{OH}$. The selectivity of the graphene/Au/ Cys-PP-Cd ${ }^{2+}$ FET sensor is evaluated by monitoring the current signals induced by metal ions (Fig. 2e) and other potential interferents (Fig. 2f) that may coexist in biological systems. The low response to metal ions is an indication of high quality of 
a

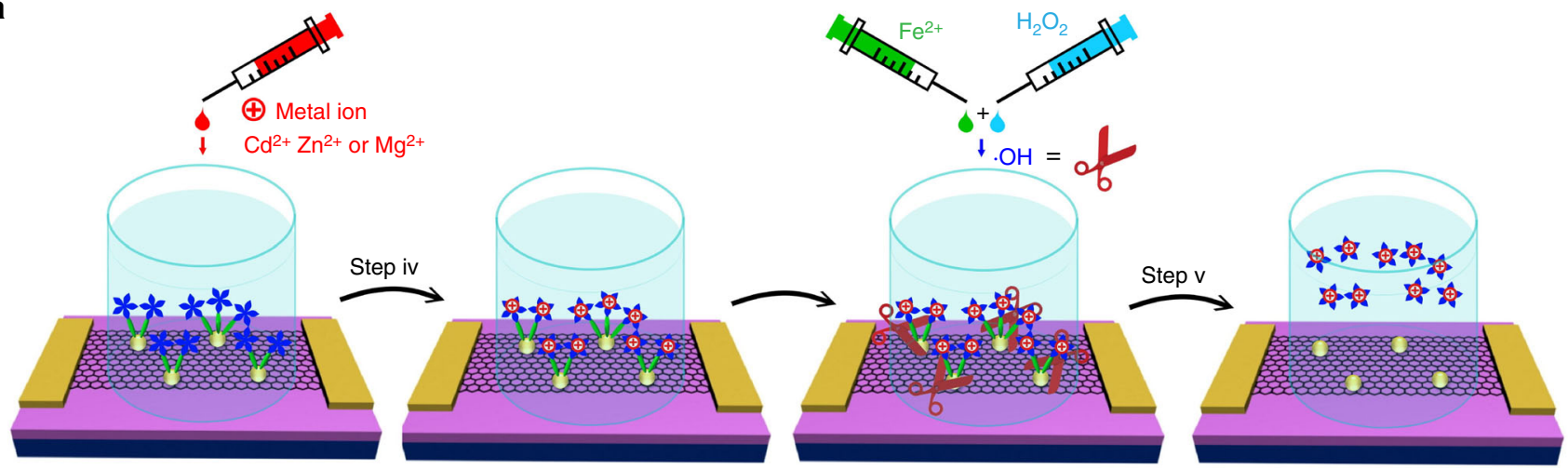

b

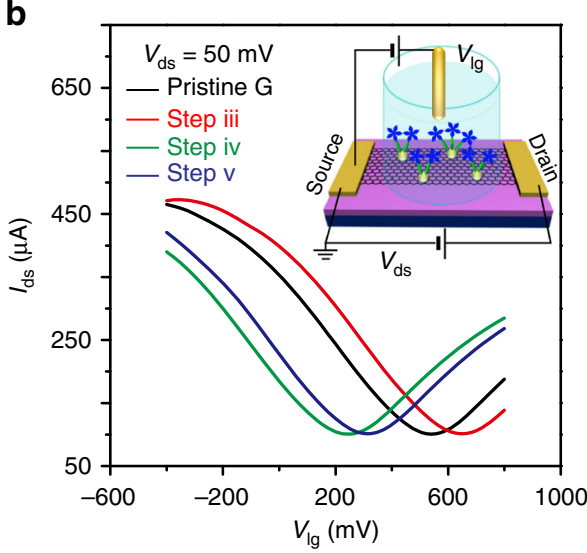

C
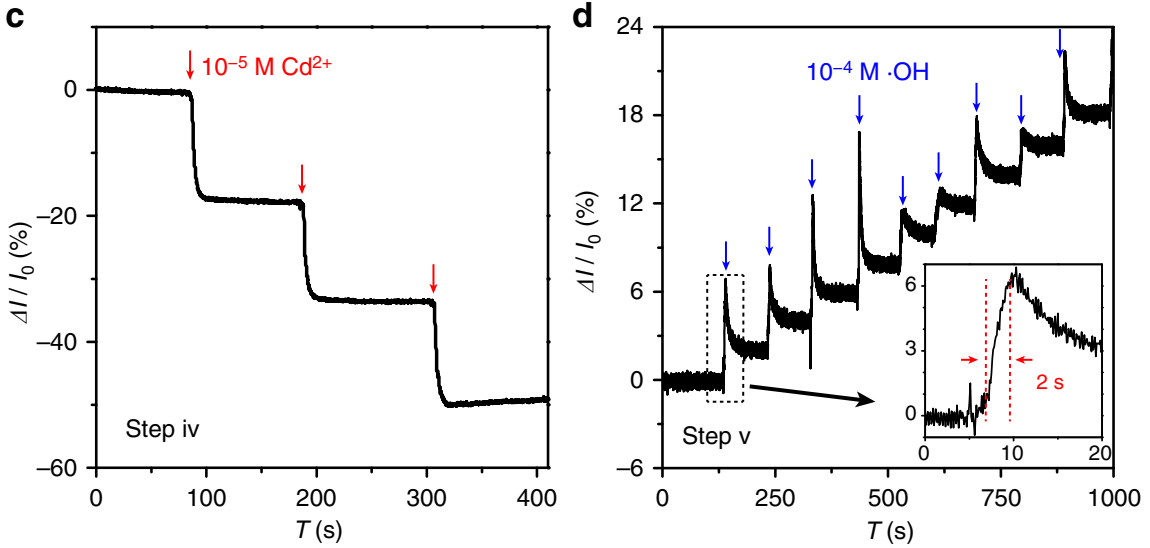

e

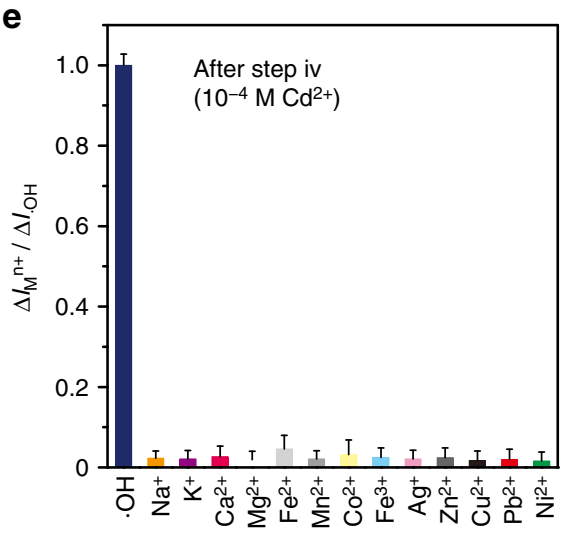

$\mathbf{f}$

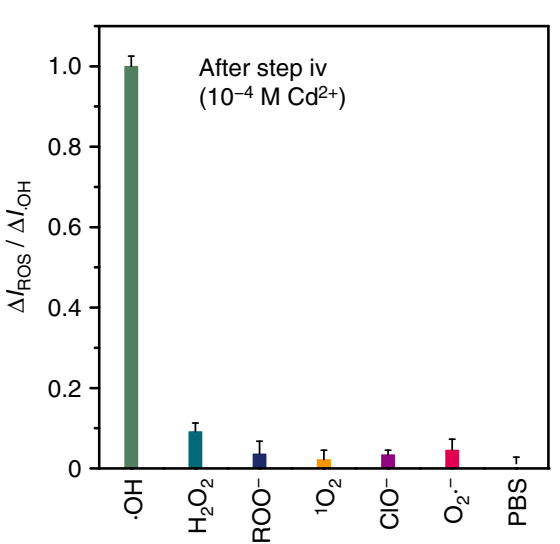

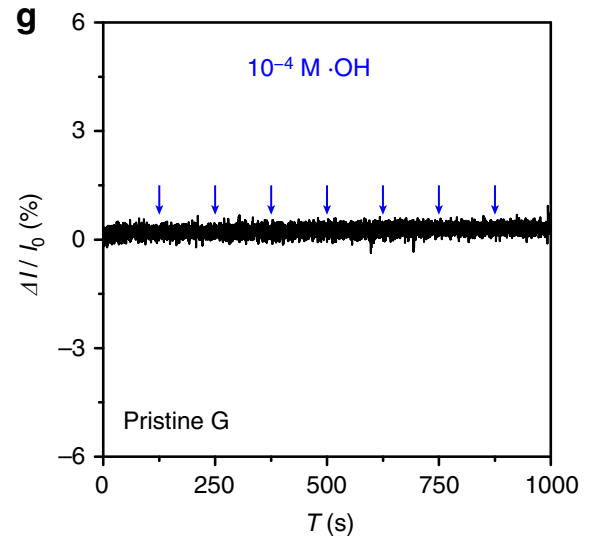

Fig. 2 Detection performance and mechanism of the field-effect transistor (FET) sensor. a Schematic diagram of the $\cdot \mathbf{O H}$ detection. $\mathbf{b}$ Liquid gate transfer curves of a FET device of pristine graphene (black), after step iii (red), after step iv (10-4 $\mathrm{M} \mathrm{Cd}^{2+}$, green), and after step $\vee\left(10^{-4} \mathrm{M} \cdot \mathrm{OH}^{-}\right.$blue), when liquid gate voltage $\left(V_{l g}\right)$ varies from -400 to $800 \mathrm{mV}$. c, d Real-time electrical responses of a graphene/Au/Cys-PP FET device upon successive addition of $1 \times 10^{-5} \mathrm{M} \mathrm{Cd}^{2+}$ (step iv) and subsequent $1 \times 10^{-4} \mathrm{M} \cdot \mathrm{OH}$ (step v). e Selectivity of a graphene/Au/Cys-PP-Cd $2+$ FET sensor (modified in $\left.10^{-4} \mathrm{M} \mathrm{Cd}^{2+}\right)$ toward $\cdot \mathrm{OH}\left(10^{-6} \mathrm{M}\right)$ and metal ions $\left(\mathrm{Na}^{+}, \mathrm{K}+, \mathrm{Ca}^{2+}, \mathrm{Mg}^{2+}, \mathrm{Fe}^{2+}, \mathrm{Mn}^{2+}, \mathrm{Co}^{2+}, \mathrm{Fe}^{3+}, \mathrm{Ag}^{+}, \mathrm{Zn}^{2+}, \mathrm{Cu}^{2+}, \mathrm{Pb}^{2+}, \mathrm{Ni}^{2+}, 10^{-6} \mathrm{M}^{2} . \mathbf{f} \mathrm{Selectivity}\right.$ of a graphene/Au/Cys-PP-Cd ${ }^{2+}$ FET sensor (modified in $10^{-4} \mathrm{M} \mathrm{Cd}^{2+}$ ) toward $\cdot \mathrm{OH}\left(10^{-6} \mathrm{M}\right)$ and other reactive oxygen species $\left(\mathrm{H}_{2} \mathrm{O}_{2}, \mathrm{ROO}^{-},{ }^{1} \mathrm{O}_{2}\right.$, $\mathrm{ClO}^{-}, \mathrm{O}_{2} \cdot-$, phosphate-buffered saline, $10^{-6} \mathrm{M}$ ). $\mathbf{g}$ The response of a pristine graphene channel (without modification) upon successive addition of $1 \times 10^{-4} \mathrm{M} \cdot \mathrm{OH}$. The error bars are defined by the standard deviation of the results from three parallel experiments

the graphene $44-46$, as no binding with ions is expected and the pristine graphene is intrinsically insensitive to outside metal ions or $\mathrm{pH}$ variance owing to the ideal surface with pure saturated carbon bonds. When exposed to possible ROS interferents, such as $\mathrm{H}_{2} \mathrm{O}_{2}$, a little current change is observed. The negligible response $(<10 \%)$ upon the same concentration of metal ions or ROS over $\bullet \mathrm{OH}$ suggests the high selectivity of the present sensor for detecting $\bullet \mathrm{OH}$ against metal ions and other coexisting biological molecules. Moreover, the storage stability of the graphene/Au/Cys-PP-Cd ${ }^{2+} \mathrm{FET}$ sensor is investigated by monitoring the current response to $10^{-4} \mathrm{M} \cdot \mathrm{OH}$ three times daily after storage in a refrigerator, and the current response when adding $10^{-4} \mathrm{M} \cdot \mathrm{OH}$ still retains $>94.5 \%$ of its initial response after 1 week of storage (Supplementary Fig. 6).

Besides $\mathrm{Cd}^{2+}$, other metal ions such as $\mathrm{Zn}^{2+}$ and $\mathrm{Mg}^{2+}$, which can coordinate with $\mathrm{PP}$, are also used as indicators to modify the graphene/Au/Cys-PP FET device, thus the biological compatibility can be improved as a result of avoiding the usage of heavy metal ions. Considering the small leakage current with a fluctuation around $1 \mathrm{nA}\left(<0.0005 \%\right.$ of the $\left.I_{\mathrm{ds}}\right)$ in 
a

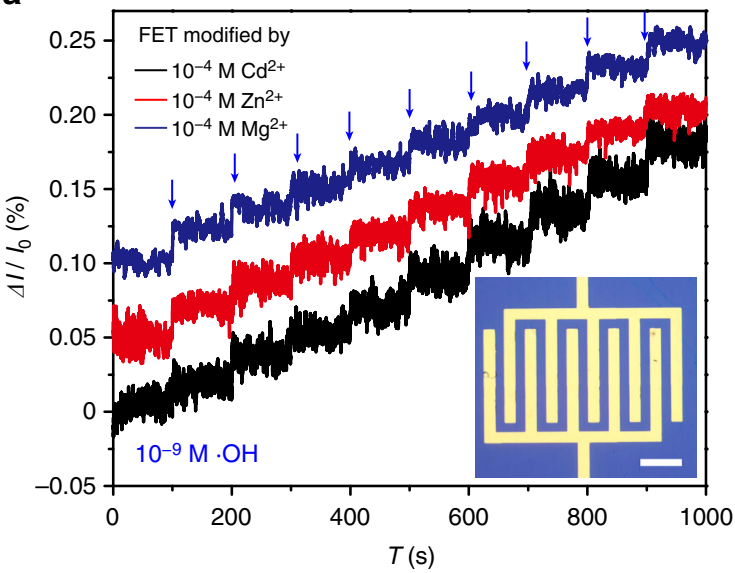

C

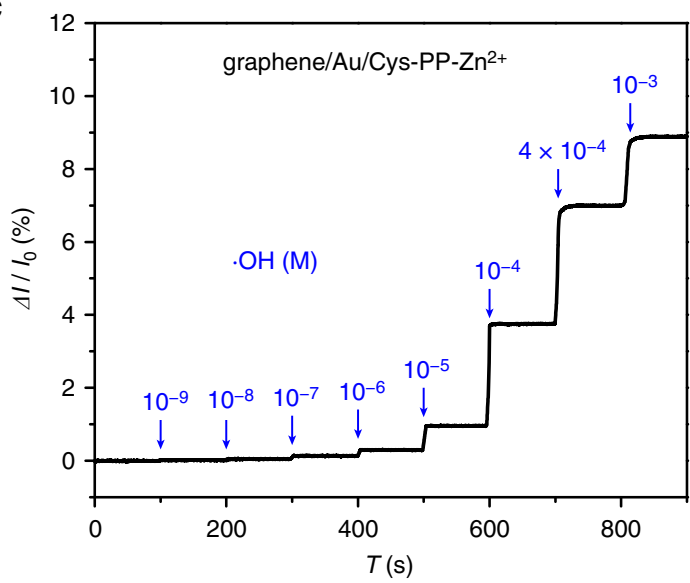

b

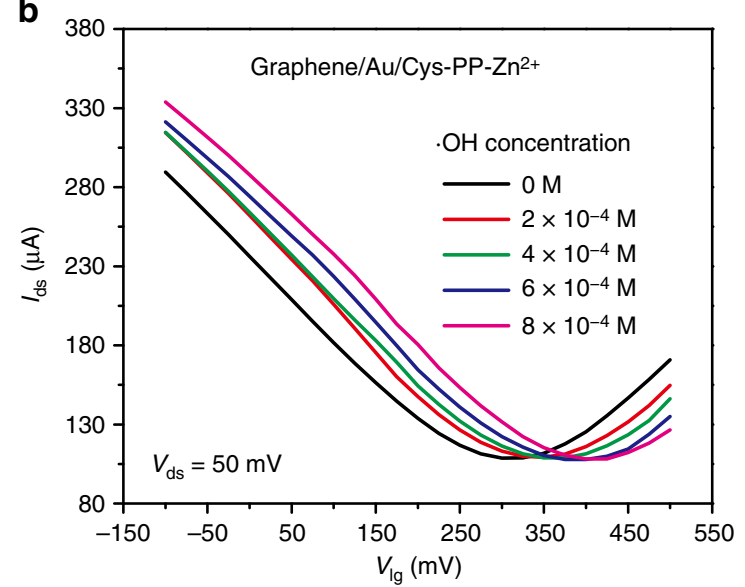

d

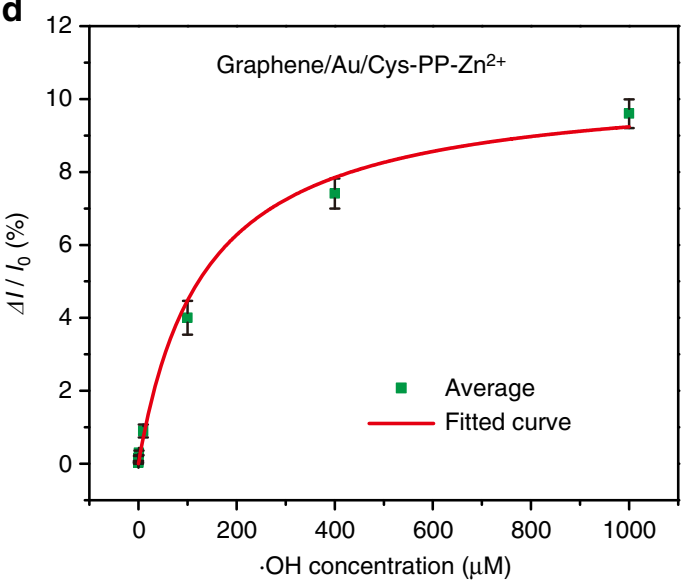

Fig. 3 The field-effect transistor (FET) sensor with $\mathrm{Cd}^{2+}, \mathrm{Zn}^{2+}$, and $\mathrm{Mg}^{2+}$ as the indicator. a Real-time electrical responses of a graphene/Au/Cys-PPmetal ion FET device (modified in $10^{-4} \mathrm{M} \mathrm{Cd}^{2+}, \mathrm{Zn}^{2+}$, or $\mathrm{Mg}^{2+}$ ) upon successive addition of $10^{-9} \mathrm{M} \cdot \mathrm{OH}$. The inset shows the FET device with interdigital electrodes. $\mathbf{b}$ Liquid gate transfer curves $\left(V_{\mathrm{ds}}=50 \mathrm{mV}\right.$ ) of a graphene/Au/Cys-PP- $\mathrm{Zn}^{2+}$ FET device (modified in $10^{-4} \mathrm{M} \mathrm{Zn^{2+ }}$ ) before and after addition of $2 \times 10^{-4}, 4 \times 10^{-4}, 6 \times 10^{-4}$, and $8 \times 10^{-4} \mathrm{M} \cdot \mathrm{OH}$, when $V_{\mathrm{lg}}$ varies from -100 to $500 \mathrm{mV}$. c Real-time response upon various concentrations of $\bullet \mathrm{OH}$ (from $10^{-9}$ to $10^{-4} \mathrm{M}$ ) for the graphene/Au/Cys-PP-Zn²+ FET device (modified in $10^{-4} \mathrm{M} \mathrm{Zn}^{2+}$ ). $\mathbf{d}$ The electrical responses versus the $\cdot \mathrm{OH}$ concentration for the graphene/Au/Cys-PP-Zn ${ }^{2+}$ FET device (modified in $10^{-4} \mathrm{M} \mathrm{Zn}^{2+}$ ). The scale bar in $\mathbf{a}$ is $200 \mu \mathrm{m}$. The error bars are defined by the standard deviation of the results from three parallel experiments

$0.01 \times$ phosphate-buffered saline (PBS; Supplementary Fig. 7), the interdigital electrodes ( $50 \mu \mathrm{m}$ channel length, Fig. 3a) can directly be used as the source-drain electrodes in the FET sensor. Owing to the small channel length, an improved sensitivity is achieved and the current response can still be detectable after modifying the graphene/Au/Cys-PP FET device with $10^{-4} \mathrm{M} \mathrm{Cd}^{2+}, 10^{-4} \mathrm{M}$ $\mathrm{Zn}^{2+}$, or $10^{-4} \mathrm{M} \mathrm{Mg}^{2+}$, when the concentration of $\cdot \mathrm{OH}$ decreases to $10^{-9} \mathrm{M}$ (Fig. 3a, Supplementary Figs. 8 and 9).

Free radical detection mechanism. FET is a device in which a gate electric field controls the current flow through the conducting channel ${ }^{47}$. When operating in solution, the gate electric field can be applied via the electrolyte/semiconductor interface, where an electrical double-layer exists that enables fast device response and low voltage operation ${ }^{20}$. Figure $1 \mathrm{~g}$ shows the output curves of a graphene/Au/Cys-PP FET device at different backgate voltages $\left(V_{\mathrm{bg}}\right)$. The linear nature of the $I_{\mathrm{ds}}$ versus drainsource voltage $\left(V_{\mathrm{ds}}\right)$ curve reveals an ideal Ohmic contact between the channel and the electrode, and such reliable contact provides the possibility of the application in sensitive sensors. The Ohmic contact remains at different $V_{\mathrm{bg}}$, suggesting that the current changes are mainly affected by the electrostatic gate doping effect, rather than the contact resistance. The $I_{\mathrm{ds}}$ versus liquid gate voltage $\left(V_{\mathrm{lg}}\right)$ (liquid gate transfer curve, $V_{\mathrm{ds}}=50 \mathrm{mV}$, Fig. 2b) shows that the FET device has an ambipolar property. The Dirac point of the pristine graphene is located at around $540 \mathrm{mV}$ and the $I_{\mathrm{ds}}$ increases by about $360 \mu \mathrm{A}$ when negatively increasing $V_{\mathrm{lg}}$ from 540 to $-400 \mathrm{mV}$. Owing to the chemical doping effect, the Dirac point shifts to around $650 \mathrm{mV}$ after modification with $\mathrm{Au}$ NPs and Cys-PP. Near zero gate voltage, the graphene/ $\mathrm{Au} / \mathrm{Cys}-\mathrm{PP}$ channel shows a typical p-type behavior. Therefore, real-time responses in this study are measured in the p-type region.

The FET sensor is the combination of a sensor and an amplifier, in which a small potential alteration may induce a pronounced change of channel current ${ }^{16,48}$. The sensing process takes place at the electrolyte/semiconductor interface. The binding of charged species or the charge transfer at the interface lead to a variation of charge or electric potential of the conducting channel, in a way similar to applying an external potential to the gate electrode in a conventional FET device, leading to electrical conductivity changes associated with the analyte in real time ${ }^{16,48}$. Graphene combines extremely high charge mobility with atomic thickness, all the charge carriers in graphene flow solely on the surface and expose directly to the sensing environment, and thus the electrical property of graphene after appropriate modification 
is highly sensitive to the minute specific electrochemical perturbations imposed by the surrounding environment in solution. However, some free radicals like $\bullet \mathrm{OH}$ have high reactivity and ultra-short lifetime. The lifetime of $\bullet \mathrm{OH}$ is only around $3 \times 10^{-6} \mathrm{~s}^{36}$, orders of magnitude shorter than normal free radicals like $\bullet \mathrm{O}_{2}^{-}(\sim 1 \mathrm{~s} \text { in aqueous solution })^{37}, \bullet \mathrm{NO}(0.09$ to $>2 \mathrm{~s})^{49}$, etc. The $\cdot \mathrm{OH}$ is easy to convert to $\mathrm{H}_{2} \mathrm{O}_{2}$ or other ROS without arising current responses in the channel. Thus it is still difficult to directly monitor the highly reactive free radicals like - $\mathrm{OH}$ in the aqueous environment, although these radicals have a doping effect to graphene $e^{33,34}$. The control experiment also shows that no critical changes in the current are detected (Fig. $2 \mathrm{~g}$ ), when successively adding $1 \times 10^{-4} \mathrm{M} \bullet \mathrm{OH}$ on a pristine graphene FET device.

To solve this problem, an inner-cutting strategy (Fig. 2a) is developed to achieve an indirect label-free detection of $\bullet \mathrm{OH}$. The graphene channel is functionalized with metal ions via $\mathrm{Au}-\mathrm{S}$ bonds of the cysteamine. The $\cdot \mathrm{OH}$ reacts with thiol derivatives with rate constant in the range of $10^{9}-10^{10} \mathrm{M}^{-1} \mathrm{~S}^{-1},>4$ orders of magnitude faster than other ROS, such as $\mathrm{H}_{2} \mathrm{O}_{2}\left(0.9 \mathrm{M}^{-1} \mathrm{~S}^{-1}\right)^{5}$ and $\cdot \mathrm{O}_{2}^{-}\left(10^{4}-10^{5} \mathrm{M}^{-1} \mathrm{~S}^{-1}\right)^{50}$. After the reaction, the XPS spectra of the graphene/Au/Cys-PP-Cd ${ }^{2+}$ (Fig. 1d-f) show that the $\mathrm{Au} 4 f$ peaks maintain while the $\mathrm{S} 2 p$ and $\mathrm{N} 1 s$ peaks disappear, indicating successful cutting of Cys-PP-Cd ${ }^{2}+$ from Au NPs. Thus the ultra-fast reaction enables selective cut of the cysteamine by - $\mathrm{OH}$ and releases metal ions in spite of the ultra-short lifetime of - $\mathrm{OH}$, leading to a controllable surface charge doping or dedoping of the graphene. Figure $2 c$ and Supplementary Figs. 10 and 11 display the real-time responses of the graphene/Au/CysPP FET device during a cumulative addition of $\mathrm{Cd}^{2+}$ or $\mathrm{Zn}^{2+}$. The current decreases with increasing metal ion concentration and reaches saturation until the concentration increase to $\sim 10^{-4}$ M. The Dirac point of the graphene/Au/Cys-PP FET negatively shifts by $420 \mathrm{mV}$ after modification in $10^{-4} \mathrm{M} \mathrm{Cd}^{2+}$ (Fig. 2b), which is attributed to the coordination reaction of $\mathrm{Cd}^{2+}$ with the $\mathrm{PP}$ on the graphene channel. The corresponding charge density of the bonded $\mathrm{Cd}^{2+}$ is estimated to be $0.1 \mathrm{~nm}^{-2}$ (Supplementary Note 2). Considering the fact that the distance between $\mathrm{Cd}^{2+}$ and graphene is within the Debye length (Supplementary Note 3$)^{51}$, the positive electrical field of the bonded $\mathrm{Cd}^{2+}$ forces the positively charged holes away from the electrolyte/graphene interface owing to the electrostatic gating effect. Thus it decreases the hole concentration in the graphene sheet and leads to negative current response of the graphene/Au/Cys-PP FET device ${ }^{31,52}$. When the $\bullet \mathrm{OH}$ is added into the electrolyte by Fenton reaction, the self-assembled monolayer of cysteamine is destroyed by the highly reactive $\cdot \mathrm{OH}$, leading to release of metal ions from the electrolyte/graphene interface. Owing to surface charge dedoping, the current recovers (Figs. $2 \mathrm{~d}$ and 3a, Supplementary Figs. 8 and 9), and the Dirac point of the graphene/Au/Cys-PP$\mathrm{Cd}^{2+}$ FET positively shifts by $57 \mathrm{mV}$ upon addition of $10^{-4} \mathrm{M}$ - $\mathrm{OH}$ (Fig. $2 \mathrm{~b}$ ), thus the $\bullet \mathrm{OH}$ radicals are indirectly detected. The device exhibits ultrahigh sensitivity to the concentration change of the metal ions. Remarkable response is obtained even when the concentration change of $\mathrm{Cd}^{2+}$ decreases to $10^{-10} \mathrm{M}$ (Supplementary Fig. 14). The sensitivity of the graphene/Au/Cys-PP FET to the concentration change of $\mathrm{Cd}^{2+}$ is among the highest values of graphene-based FET metal ion sensors ${ }^{17,19-22,30-32}$, which brings the possibility of the indirect detection of $\bullet \mathrm{OH}$ with high sensitivity.

To prove the inner-cutting mechanism, we measured the graphene/Au/Cys-PP-Cd ${ }^{2+} \mathrm{FET}$, the graphene/Au/Cys-PP- $\mathrm{Zn}^{2+}$ FET, and the graphene/Au/Cys-PP-Mg ${ }^{2+}$ FET upon successive addition of $2 \times 10^{-4} \mathrm{M} \cdot \mathrm{OH}$. Both the liquid gate transfer curves and the back gate transfer curve (Fig. 3b, Supplementary Figs. 12 and 13) gradually shift positively and the current reaches saturation until the $\cdot \mathrm{OH}$ concentration increases to $\sim 10^{-3} \mathrm{M}$ (Fig. 3c). Percentage change in $I_{\mathrm{ds}}\left(\Delta I / I_{0}\right)$ increases stepwise at each concentration. Figure $3 \mathrm{~d}$ shows $\Delta I / I_{0}$ plotted as a function of the $\cdot \mathrm{OH}$ concentration from $10^{-9}$ to $10^{-3} \mathrm{M}$, which can be described by the Hill-Langmuir equation ${ }^{19,53,54}$ :

$$
\frac{\Delta \mathrm{I}}{I_{0}}=\frac{\left(\frac{\Delta \mathrm{I}}{I_{0}}\right)_{\max } C_{\bullet \mathrm{OH}}}{K_{\mathrm{D}}+C_{\bullet \mathrm{OH}}}
$$

where $\left(\Delta I / I_{0}\right)_{\max }$ is the saturated value of the $\Delta I / I_{0}, C_{. \mathrm{OH}}$ is the - $\mathrm{OH}$ concentration, and $K_{\mathrm{D}}$ is a constant related to the ability of the $\cdot \mathrm{OH}$ to cut the Au-S bonds. The $K_{\mathrm{D}}$ value is extracted from the fitted curve to be about $9.95 \mu \mathrm{M}$, indicating the relatively high reactivity between $\cdot \mathrm{OH}$ and $\mathrm{Au}-\mathrm{S}$ bonds.

The selective detection of $\cdot \mathrm{OH}$ is attributed to its high reactivity among the ROS. The redox potential of $\bullet \mathrm{OH}$ is $2.31 \mathrm{~V}$, higher than other ROS such as $\bullet \mathrm{O}_{2}^{-}(0.94 \mathrm{~V}), \mathrm{H}_{2} \mathrm{O}_{2}(0.32 \mathrm{~V})$, and ROO- $(0.77 \mathrm{~V})^{5}$. The redox potential is defined compared with $\mathrm{H}_{2} / \mathrm{H}^{+}$to represent the affinity of a substance for electrons. Higher potential means larger inclination to obtain electrons and stronger oxidizability, thus the cysteamine is inclined to react with $\bullet \mathrm{OH}$ rather than other ROS. This, as well as higher reaction rate constant of $\bullet \mathrm{OH}$ with the cysteamine compared with other ROS, gives rise to selective reaction of $\bullet \mathrm{OH}$ and cysteamine and endows the FET sensor with fast response and high selectivity (Fig. 2e, f).

Quasi-quantitative detection. Non-linear response of the current to different concentrations of $\bullet \mathrm{OH}$ (Fig. 3c, d) indicates that the graphene/Au/Cys-PP-metal ion FET, similar to other FET sensors ${ }^{19-22}$, cannot be directly used in quantitatively monitoring the $\bullet \mathrm{OH}$. However, the high controllability of the surface charge doping by metal ions allows a quasi-quantitative detection. Figure 4 shows the real-time current response to different concentrations of $\bullet \mathrm{OH}$, after exposing the graphene/Au/ Cys-PP FET devices to aqueous solutions with $10^{-4}, 10^{-5}$, or $10^{-6} \mathrm{M} \mathrm{Cd}^{2+}$, respectively. $10^{-4} \mathrm{M} \cdot \mathrm{OH}$ is detectable when the device has been exposed to $10^{-6} \mathrm{M} \mathrm{Cd}^{2+}$ (Fig. 4a), while the detectable concentration decreases to $10^{-7} \mathrm{M} \cdot \mathrm{OH}$ after exposing the device to $10^{-4} \mathrm{M} \mathrm{Cd}^{2+}$ (Fig. 4c). The increased $\bullet \mathrm{OH}$ sensitivity should be attributed to the enhanced surface doping or de-doping effect. It is because that, after exposure in high concentration metal ions, more positively charged metal ions are bonded on the graphene surface. As a result, when a certain concentration of $\bullet \mathrm{OH}$ is added, more metal ions are released from the electrolyte/graphene interface and larger current response is expected. Therefore, the sensitivity of the $\bullet$ OH FET can be tuned by the amount of surface-bonded metal ions.

The quasi-quantitative detection is achieved by monitoring the - $\mathrm{OH}$ using FET sensors with different sensitivities. For instance, two graphene/Au/Cys-PP FET devices are exposed in $10^{-5} \mathrm{M}$ (Fig. 4d) and $10^{-4} \mathrm{M} \mathrm{Cd}^{2+}$ (Fig. 4e), respectively, resulting in FET sensors with different $\bullet \mathrm{OH}$ sensitivities. When adding $10^{-5}$ $\mathrm{M} \cdot \mathrm{OH}$ solution onto the devices, the sensors exhibit different real-time responses (Fig. 4f). The current of the device exposed in $10^{-4} \mathrm{M} \mathrm{Cd}^{2+}$ varies by $\sim 4 \%$. According to the result in Fig. $4 \mathrm{c}$, the $\cdot \mathrm{OH}$ concentration should be $\geq 10^{-5} \mathrm{M}$. In the case of the device exposed in $10^{-5} \mathrm{M} \mathrm{Cd}^{2+}$, the current response is $<1 \%$. The - $\mathrm{OH}$ concentration should be $\leq 10^{-5} \mathrm{M}$. Therefore, the $\cdot \mathrm{OH}$ concentration should be at a level of $10^{-5} \mathrm{M}$, and a quasiquantitative detection is realized with the aid of controllable surface charge doping by metal ions.

Detection of $\bullet \mathrm{OH}$ produced by living cells. The $\bullet \mathrm{OH}$ plays an important role in the living system. As an application, the FET sensors are used for real-time detection of $\bullet \mathrm{OH}$ produced by 


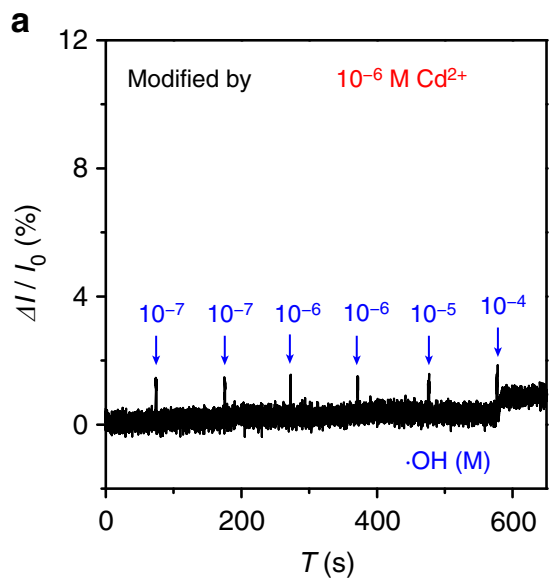

d

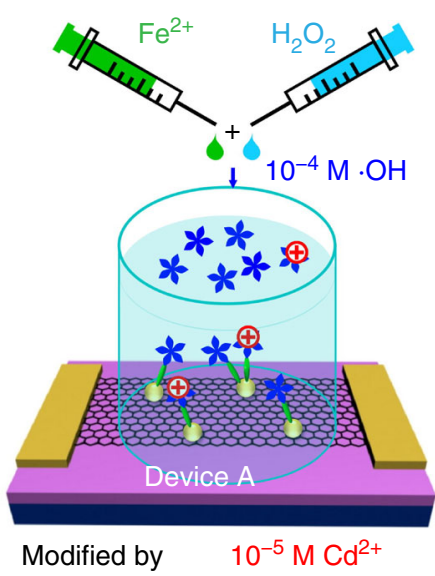

b

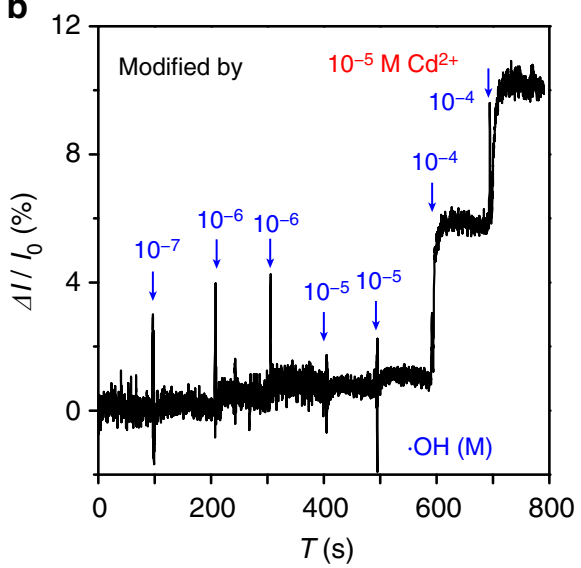

e

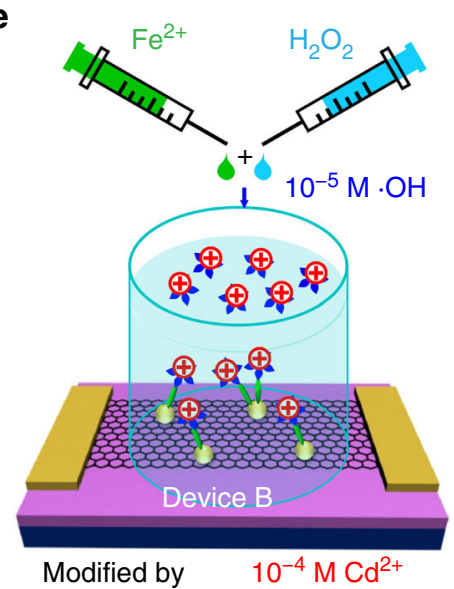

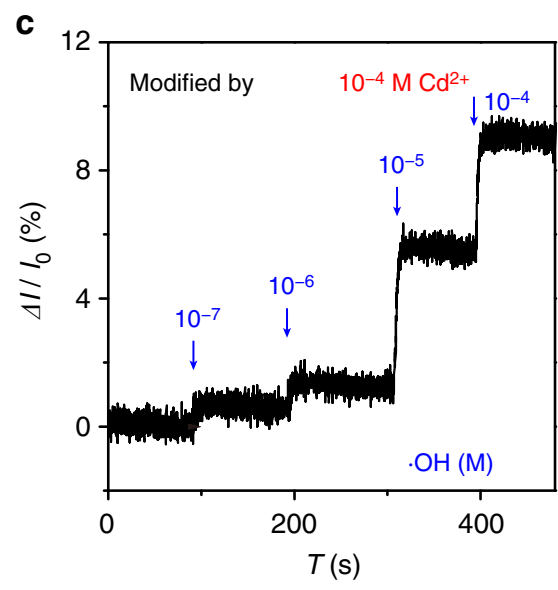

$\mathbf{f}$

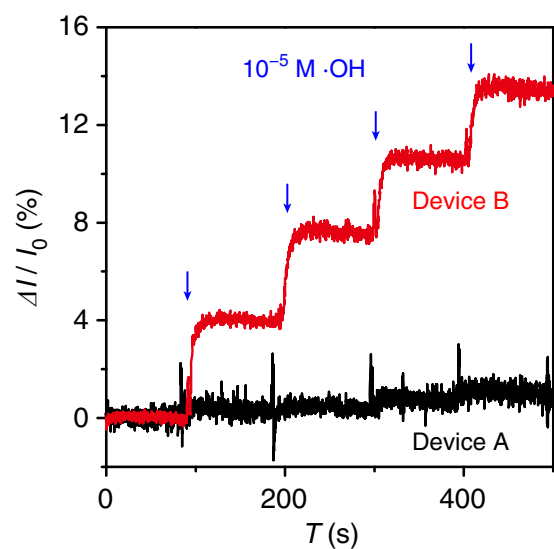

Fig. 4 Quasi-quantitative detection of $\cdot \mathrm{OH}$. a-c Real-time response upon various concentrations of $\cdot \mathrm{OH}$ (from $10^{-7}$ to $10^{-4} \mathrm{M}$ ) for the field-effect transistor (FET) sensors with channel doped with $\mathbf{a} 10^{-6} \mathrm{M} \mathrm{Cd}^{2+}, \mathbf{b} 10^{-5} \mathrm{M} \mathrm{Cd}^{2+}$, or $\mathbf{c} 10^{-4} \mathrm{M} \mathrm{Cd}^{2+}$. d, e Schematic diagram of the detection of $\cdot \mathrm{OH}$ using the FET sensors modified by different concentrations of $\mathrm{Cd}^{2+}$. $\mathbf{f}$ Real-time response upon successive addition of $10^{-5} \mathrm{M} \cdot \mathrm{OH}$ for the FET sensors with channel doped with $10^{-5} \mathrm{M} \mathrm{Cd}^{2+}$ (black, Device A) and $10^{-4} \mathrm{M} \mathrm{Cd}^{2+}$ (red, Device B)

living cells within hours (Fig. 5a). Considering the bio-compatibility, $\mathrm{Zn}^{2+}$ was used as the indicator in the sensor. Hela cells were cultured on the surface of the graphene/Au/Cys-PP- $\mathrm{Zn}^{2+}$ FET sensor with interdigital source-drain electrodes (Fig. 5b, Supplementary Fig. 15). In the testing, lipopolysaccharide (LPS, $10 \mu \mathrm{g} \mathrm{mL}^{-1}$ ) was added as a stimulus to induce oxidative stress for the production of ROS within the Hela cells ${ }^{9}$. To verify the intercellular generation of ROS, the cells are incubated in $2^{\prime}, 7^{\prime}$ dichlorodihydrofluorescein diacetate (DCFH-DA) solution, which functions as the fluorescent probe for $\bullet \mathrm{OH}$. The probe is monitored by confocal microscopy upon $488 \mathrm{~nm}$ excitation. From the overlay image of the confocal fluorescence image and bright-field image (Fig. 5b-d), it is clear that the $\bullet \mathrm{OH}$ has been generated in the Hela cells. As a comparison, no fluorescence (Supplementary Fig. 16) is observed without addition of LPS. Owing to the ultra-short lifetime, the intercellular $\cdot \mathrm{OH}$ is hard to directly penetrate the cell membrane before converting to other kinds of ROS (i.e., $\left.\mathrm{H}_{2} \mathrm{O}_{2}, \bullet \mathrm{O}_{2}^{-}\right)^{5}$. Stable ROS (i.e., $\mathrm{H}_{2} \mathrm{O}_{2}, \bullet \mathrm{O}_{2}^{-}$) can penetrate the cell membrane, reach the solution environment $^{5}$, and generate the extracellular $\cdot \mathrm{OH}$ radicals. As a result, the graphene/Au/Cys-PP- $\mathrm{Zn}^{2+}$ FET device (modified by $10^{-4} \mathrm{M}$ $\left.\mathrm{Zn}^{2+}\right)$ has a response in $I_{\mathrm{ds}}$ when the Hela cells are stimulated by LPS (Fig. 5e). The $I_{\mathrm{ds}}$ sharply increases in the first $1000 \mathrm{~s}$ and then maintains with a total change of current percentage of about $0.18 \%$, in agreement with the response curve measured by other detection method ${ }^{10}$. When adding $1 \%$ dimethyl sulfoxide as the $\bullet \mathrm{OH}$ scavenger, the total change of $I_{\mathrm{ds}}$ reduces to about $0.03 \%$, indicating the current signal is mainly from the -OH. Without addition of LPS or using the pristine graphene as the channel, no change of the $I_{\mathrm{ds}}$ is observed.

Quasi-quantitative detection of the $\cdot \mathrm{OH}$ generated from the Hela cells is realized by using the FET sensors modified with different amount of $\mathrm{Zn}^{2+}$. The real-time current response to different concentrations of $\bullet \mathrm{OH}$ (Supplementary Fig. 17) shows that the FET sensor (modified by $10^{-5} \mathrm{M} \mathrm{Zn}^{2+}$ ) has a small change of $I_{\mathrm{ds}}$ when exposing in $10^{-7} \mathrm{M} \bullet \mathrm{OH}$, while no response is observed in the case of the FET sensor modified by $10^{-6} \mathrm{M} \mathrm{Zn}^{2+}$. According to this result, the current response of different FET sensors upon the addition of $10 \mu \mathrm{g} \mathrm{mL}^{-1}$ LPS indicates the extracellular $\bullet \mathrm{OH}$ concentration is at a level of $\sim 10^{-7} \mathrm{M}$. This amount is lower than the intracellular concentration $\left(10^{-6} \mathrm{M}\right)$ measured by other methods ${ }^{9-11}$, in correspondence with the fact that the extracellular $\bullet \mathrm{OH}$ originates from other ROS released from the cells and the production of $\bullet \mathrm{OH}$ is relatively low (i.e., the rate constant of $\mathrm{H}_{2} \mathrm{O}_{2}+\cdot \mathrm{O}_{2}^{-} \rightarrow \cdot \mathrm{OH}+\mathrm{OH}^{-}+\mathrm{O}_{2}$ is around $1.3 \mathrm{M}^{-1} \mathrm{~s}^{-1},<40-80 \mathrm{M}^{-1} \mathrm{~s}^{-1}$ of Fenton reaction) $)^{55,56}$.

\section{Discussion}

In this article, we realize the detection of $\bullet \mathrm{OH}$ by an inner-cutting graphene FET sensor. Highly reactive $\bullet \mathrm{OH}$ cuts the cysteamine to release $\mathrm{Cd}^{2+}$ from the electrolyte/graphene interface, leading 
a

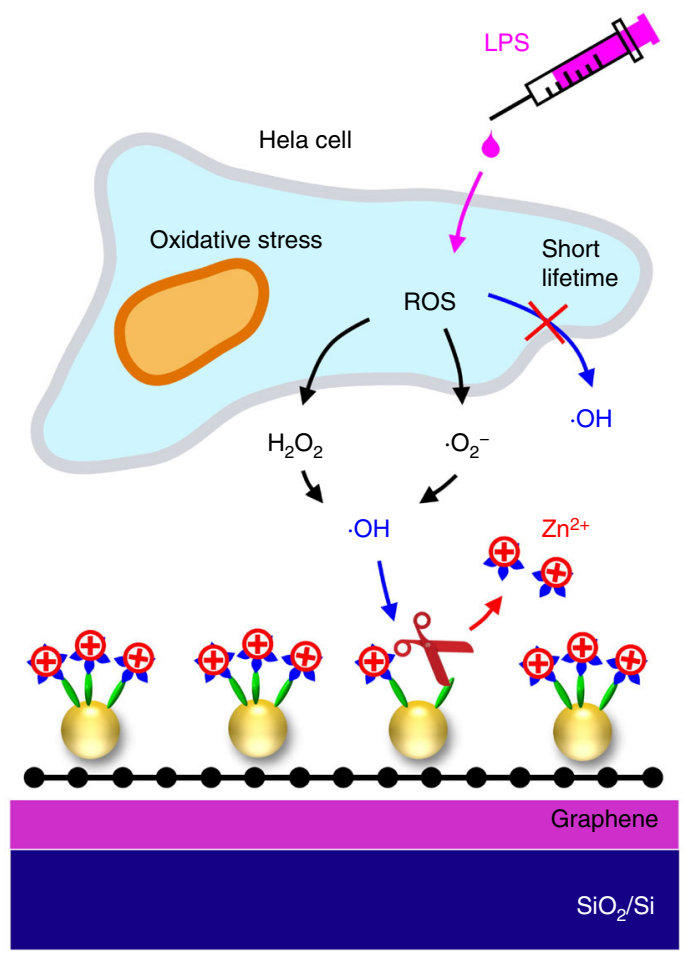

e

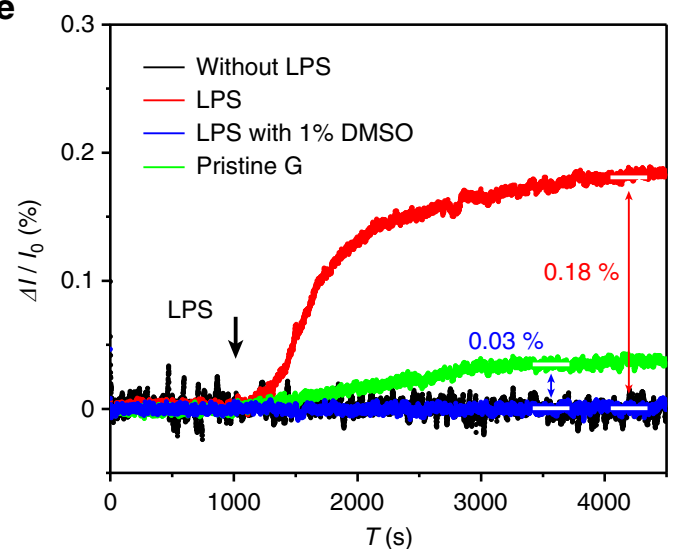

f
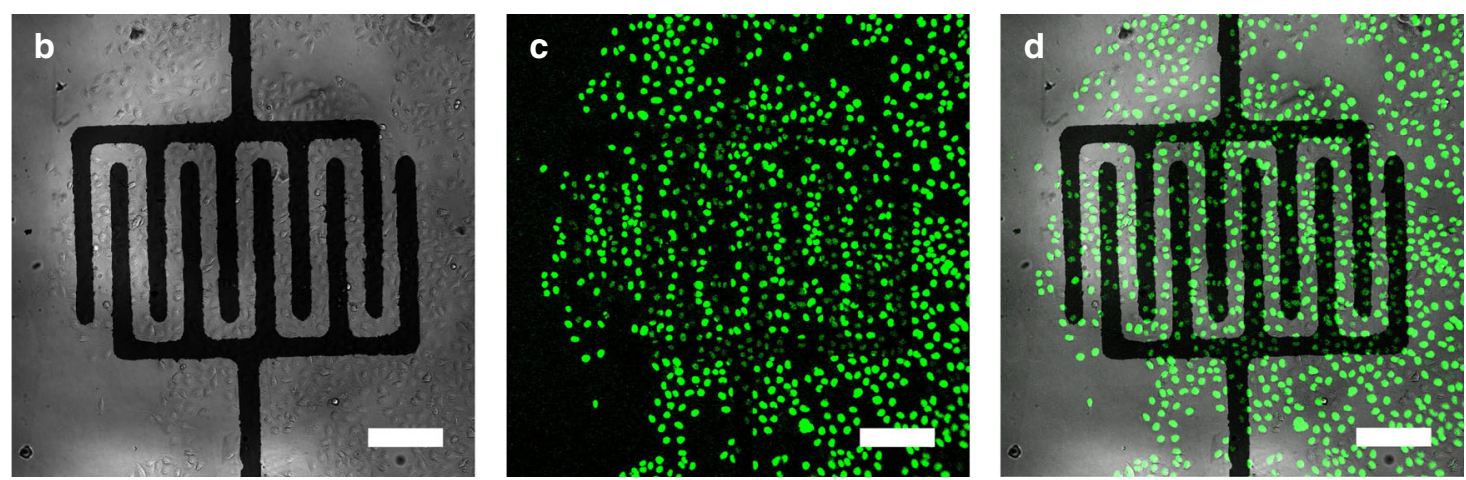

Fig. 5 Real-time detection of $\cdot \mathrm{OH}$ in living system. a Schematic diagram of the detection of $\cdot \mathrm{OH}$ produced by Hela cells. $\mathbf{b}$ Bright field image, $\mathbf{c}$ confocal fluorescence image (excited by $488 \mathrm{~nm}$ laser), and $\mathbf{d}$ overlay image of the Hela cells on a field-effect transistor (FET) senor, which indicate that the $\cdot \mathrm{OH}$ is generated intracellularly after addition of $10 \mu \mathrm{gL}^{-1}$ lipopolysaccharide (LPS). e Real-time response of the sensor (or pristine graphene) upon the $\cdot \mathrm{OH}$ generated from the Hela cells after addition of $10 \mu \mathrm{g} \mathrm{mL} \mathrm{L}^{-1} \mathrm{LPS}$ or $10 \mu \mathrm{g} \mathrm{mL} \mathrm{L}^{-1} \mathrm{LPS}$ with $1 \%$ dimethyl sulfoxide. $\mathbf{f}$ Real-time response upon the $\cdot \mathrm{OH}$ generated

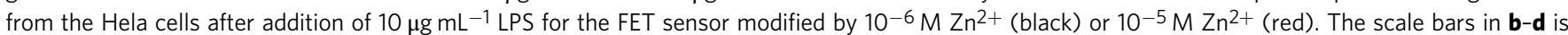
$200 \mu \mathrm{m}$

to charge de-doping of the graphene channel. This, as well as the high carrier mobility and atomic thickness of graphene, result in high sensitivity of the FET sensor. By this strategy, $\bullet \mathrm{OH}$ with a concentration down to $10^{-9} \mathrm{M}$ is detectable, comparable or higher than some of the conventional free radical detection techniques (i.e., $10^{-6} \mathrm{M} \cdot \mathrm{OH}$ for fluorescence spectroscopy) ${ }^{9,11}$. The inner-cutting strategy can not only monitor $\bullet \mathrm{OH}$ but also has the potential to detect other types of highly reactive free radicals. Compared with other detection technologies like ESR spectroscopy and fluorescence spectroscopy, the inner-cutting graphene FET sensor is a portable and user-friendly analytical platform that realizes label-free real-time detection with both high selectivity and sensitivity. More importantly, based on the controllable charge doping and de-doping by metal ions, the $\bullet \mathrm{OH}$ generated from the Hela cells can be quasi-quantitatively measured by using the graphene/Au/Cys-PP- $\mathrm{Zn}^{2+}$ FET sensors with different amount of $\mathrm{Zn}^{2+}$ dopant, indicating that the FET sensor is compatible with living system when non-heavy metal ions are used as the indicator, and the figure of merit still maintains when detecting in living system since $10^{-7} \mathrm{M}$ extracellular $\bullet \mathrm{OH}$ can be readily detected. This work extends the application of FET sensors in monitoring highly reactive free radical and realizes a real-time quasi-quantitative detection in living environment. Such a portable and user-friendly free radical FET sensor has 
great potential for practical applications in biological research, human health, environmental monitoring, etc.

\section{Methods}

Fabrication of the FET sensor. A monolayer graphene film was produced by CVD (Supplementary Note 1) and transferred onto a clean $\mathrm{SiO}_{2} / \mathrm{Si}$ substrate to fabricate a FET device by photolithography. The device was thermally annealed to improve the contacts between graphene and electrodes $(50 \mathrm{~nm} \mathrm{Au} / 5 \mathrm{~nm} \mathrm{Cr})$, and then $\mathrm{Au}$ NPs were deposited onto graphene by vacuum evaporation (Covap, Angstrom Corp.) and thermal annealing at $200^{\circ} \mathrm{C}$ for $30 \mathrm{~min}$. The resulting graphene/Au NPs was submerged in $10^{-2} \mathrm{M}$ cysteamine (Sigma-Aldrich) solution. The assembly of cysteamine on $\mathrm{Au}$ NPs was kept overnight at room temperature, followed by rinsing with ethanol for several times to remove extra cysteamine. The cysteaminemodified device was immersed in $10^{-5} \mathrm{M}$ PP (Sigma-Aldrich) and $N, N$-dimethylformamide (DMF) solution for $15 \mathrm{~h}$, by adding 1-ethyl-3-(3-dimethylaminopropyl) carbodiimide (Sigma-Aldrich) and $N$-hydroxysuccinimide (Sigma-Aldrich) as the catalysts. The resulting FET sensor, with immobilized PP, was rinsed with DMF, acetone, ethanol, and distilled water in sequence to remove extra residues. The graphene/Au/Cys-PP was dipped in $\mathrm{Cd}^{2+}, \mathrm{Zn}^{2+}$, or $\mathrm{Mg}^{2+}$ solution for $6 \mathrm{~h}$ before tests. Owing to the coordination reaction with $\mathrm{PP}, \mathrm{Cd}^{2+}, \mathrm{Zn}^{2+}$, or $\mathrm{Mg}^{2+}$ was bound to the surface of FET to charge-dope graphene. A solution chamber, which was employed in all solution-based measurements, was fabricated by a threedimensional printer.

Characterization. The samples were measured by XPS (Perkin-Elmer PHI5300 with $250 \mathrm{~W}$ Mg Ka source), Raman (HORIBA XploRA, $532 \mathrm{~nm}$ layer), FESEM (Zeiss Ultra 55, acceleration voltage: $5 \mathrm{kV}$ ), TEM (Tecnai G2 F20 S-Twin, acceleration voltage: $200 \mathrm{kV}$ ), AFM (XE7, Parks System), and optical microscope (BH2, Olympus). The UV-vis absorption spectra (Lambda 750) were measured from the fluorine-doped tin oxide (FTO)-coated glass. The FTO-coated glass was thoroughly cleaned by sonication in the soapy water, ethanol, and $1.0 \mathrm{M} \mathrm{KOH}$ solution, followed by a rinse with doubly distilled water, and then it was dried with pure nitrogen stream and treated by the modification processes as graphene.

Device measurement. The electrical signal was measured by a semiconductor parameter analyzer (Keysight, B1500A) and a probe station (Everbeing, PE-4) at room temperature in air. The $\cdot \mathrm{OH}$ was generated through Fenton reaction by $\mathrm{H}_{2} \mathrm{O}_{2}$ and $\mathrm{Fe}^{2+}\left(\mathrm{H}_{2} \mathrm{O}_{2} / \mathrm{Fe}^{2+}=6: 1\right)$. The electrolyte was $10^{-4} \mathrm{M}$ PBS $(0.01 \times \mathrm{PBS}$, $\mathrm{pH}$ 7.2-7.4). All the aqueous solutions were prepared using distilled water with a resistivity of $18.2 \mathrm{M} \Omega \mathrm{cm}$. $\mathrm{Ag} / \mathrm{AgCl}$ reference electrode was used as the liquid gate electrode. The $V_{\mathrm{gs}}$ was set lower than $\pm 0.8 \mathrm{~V}$ (versus $\mathrm{Ag} / \mathrm{AgCl}$ ) and the $V_{\mathrm{ds}}$ was set to $50 \mathrm{mV}$ to avoid any electrochemical reaction on the electrodes.

Detection of the $\cdot \mathrm{OH}$ generated by Hela cell. Hela cells were cultured on the FET sensors (Supplementary Note 4). The fluorescent images were captured by a laser confocal microscope (A42, Nikon) using $2 \times 10^{-6} \mathrm{M}$ DCFH-DA as the fluorescent probe. The device was immersed in $0.01 \times$ PBS to keep the cells in good status and stored in a small culture dish for the measurement. Electrical measurement was performed by a semiconductor parameter analyzer (Keysight, $\mathrm{B} 1500 \mathrm{~A})$ and a probe station (Everbeing, PE-4) without applying $V_{\mathrm{lg}}$ or $V_{\mathrm{bg}}$. After the $I_{\mathrm{ds}}$ became stable for $1000 \mathrm{~s}\left(V_{\mathrm{ds}}=50 \mathrm{mV}\right)$, the electrolyte solution was quickly changed to $10 \mu \mathrm{g} \mathrm{mL}^{-1}$ LPS $(0.01 \times \mathrm{PBS})$ solution. The real-time $I_{\mathrm{ds}}$ was recorded for $4500 \mathrm{~s}$ in air.

\section{Data availability}

The data that support the findings of this study are available from the corresponding author upon request.

Received: 20 March 2018 Accepted: 7 March 2019

Published online: 04 April 2019

\section{References}

1. Halliwell, B. \& Gutteridge, J. M. C. Free Radicals in Biology and Medicine (Oxford University Press, Oxford, 1999).

2. Sonntag, C. V. Free-Radical-induced DNA Damage and its Repair (Springer, Berlin, 2006).

3. Dickinson, B. C. \& Chang, C. J. Chemistry and biology of reactive oxygen species in signaling or stress responses. Nat. Chem. Biol. 7, 504-511 (2011).

4. Giorgio, M., Trinei, M., Migliaccio, E. \& Pelicci, P. G. Hydrogen peroxide: a metabolic by-product or a common mediator of ageing signals. Nat. Rev. Mol. Cell Biol. 8, 722-728 (2007).

5. Winterbourn, C. C. Reconciling the chemistry and biology of reactive oxygen species. Nat. Chem. Biol. 4, 278-286 (2008)
6. Black, H. S. Reassessment of a free radical theory of cancer with emphasis on ultraviolet carcinogenesis. Integr. Cancer Ther. 3, 279-293 (2004).

7. Ganea, G. M., Kolic, P. E., El-Zahab, B. \& Warner, I. M. Ratiometric coumarin-neutral red nanoprobe for detection of hydroxyl radicals. Anal. Chem. 83, 2576-2581 (2011).

8. Timmins, G. S., Liu, K. J., Bechara, E. J. H., Kotake, Y. \& Swartz, H. M. Trapping of free radicals with direct in vivo EPR detection: a comparison of 5,5dimethyl-1-pyrroline-N-oxide and 5-diethoxyphosphoryl-5-methyl-1-pyrroline$\mathrm{N}$-oxide as spin traps for $\mathrm{HO} \bullet$ and $\mathrm{SO}_{4} \bullet-$. Free Radic. Biol. Med. 27, 329-333 (1999).

9. Zhuang, M., Ding, C. Q., Zhu, A. W. \& Tian, Y. Ratiometric fluorescence probe for monitoring hydroxyl radical in live cells based on gold nanoclusters. Anal. Chem. 86, 1829-1836 (2014).

10. Lee, H., Lee, K., Kim, I.-K. \& Park, T. G. Fluorescent gold nanoprobe sensitive to intracellular reactive oxygen species. Adv. Funct. Mater. 19, 1884-1890 (2009).

11. Zhao, Q. et al. Ratiometric fluorescent silicon quantum dots-Ce6 Ccomplex probe for the live cell imaging of highly reactive oxygen species. ACS Appl. Mater. Interfaces 9, 2052-2058 (2017).

12. Luo, X. \& Lehotay, D. C. Determination of hydroxyl radicals using salicylate as a trapping agent by gas chromatography-mass spectrometry. Clin. Biochem. 30, 41-46 (1997).

13. Kilinc, E. Determination of the hydroxyl radical by its adduct formation with phenol and liquid chromatography/electrochemical detection. Talanta 65, 876-881 (2005).

14. Zhu, A. W., Liu, Y., Rui, Q. \& Tian, Y. Selective and sensitive determination of hydroxyl radicals generated from living cells through an electrochemical impedance method. Chem. Commun. 47, 4279-4281 (2011).

15. Harbour, J. R., Chow, V. \& Bolton, J. R. An electron spin resonance study of the spin adducts of $\mathrm{OH}$ and $\mathrm{HO}_{2}$ radicals with nitrones in the ultraviolet photolysis of aqueous hydrogen peroxide solutions. Can. J. Chem. 52, 3549-3553 (1974)

16. Zhang, A. \& Lieber, C. M. Nano-bioelectronics. Chem. Rev. 116, 215-257 (2016).

17. An, J. H., Park, S. J., Kwon, O. S., Bae, J. \& Jang, J. High-performance flexible graphene aptasensor for mercury detection in mussels. ACS Nano 7, 10563-10571 (2013)

18. Lu, G. H., Ocola, L. E. \& Chen, J. H. Reduced graphene oxide for roomtemperature gas sensors. Nanotechnology. 20, 445502-445510 (2009).

19. Ohno, Y., Maehashi, K. \& Matsumoto, K. Label-free biosensors based on aptamer-modified graphene field-effect transistors. J. Am. Chem. Soc. 132, 18012-18013 (2010)

20. Chen, F., Qing, Q., Xia, J., Li, J. \& Tao, N. Electrochemical gate-controlled charge transport in graphene in ionic liquid and aqueous solution. J. Am. Chem. Soc. 131, 9908-9908 (2009).

21. $\mathrm{Yu}, \mathrm{C}$. et al. Ultrasensitive and selective sensing of heavy metal ions with modified graphene. Chem. Commun. 49, 6492-6494 (2013).

22. Jiang, S., Cheng, R., Ng, R., Huang, Y. \& Duan, X. F. Highly sensitive detection of mercury(II) ions with few-layer molybdenum disulfide. Nano Res. 8, 257-262 (2015)

23. Schedin, F. et al. Detection of individual gas molecules adsorbed on graphene. Nat. Mater. 6, 652-655 (2007).

24. Ang, P. K., Chen, W., Wee, A. T. S. \& Loh, K. P. Solution-gated epitaxial graphene as pH sensor. J. Am. Chem. Soc. 130, 14392-14393 (2008).

25. Cai, B. J. et al. Ultrasensitive label-free detection of PNA-DNA hybridization by reduced graphene oxide field-effect transistor biosensor. ACS Nano 3, 2632-2638 (2014)

26. Cai, B. J. et al. Gold nanoparticles-decorated graphene field-effect transistor biosensor for femtomolar MicroRNA detection. Biosens. Bioelectron. 74, 329-334 (2015).

27. Hess, L. H. et al. Graphene transistor arrays for recording action potentials from electrogenic cells. Adv. Mater. 23, 5045-5049 (2011).

28. Karni, C. T., Qing, Q., Li, Q., Fang, Y. \& Lieber, C. M. Graphene and nanowire transistors for cellular interfaces and electrical recording. Nano Lett. 10, 1098-1102 (2010).

29. Kwon, O. S. et al. An ultrasensitive, selective, multiplexed superbioelectronic nose that mimics the human sense of smell. Nano Lett. 15, 6559 (2015).

30. Chen, $\mathrm{K}$. H. et al. $\mathrm{Hg}$ (II) ion detection using thermally reduced graphene oxide decorated with functionalized gold nanoparticles. Anal. Chem. 84, 4057-4062 (2012).

31. Zhou, G. H. et al. Real-time, selective detection of $\mathrm{Pb}^{2+}$ in water using a reduced graphene oxide/gold nanoparticle field-effect transistor device. ACS Appl. Mater. Interfaces 6, 19235-19241 (2014).

32. Wang, C. Y. et al. A label-free and portable graphene FET aptasensor for children blood lead detection. Sci. Rep. 12, 1-8 (2016)

33. Choi, J., Lee, H., Kim, K.-J., Kim, B. \& Kim, S. Chemical doping of epitaxial graphene by organic free radicals. J. Phys. Chem. Lett. 1, 505-509 (2010).

34. Zhang, L. et al. Photo-induced free radical modification of graphene. Small. 9 , 114-1143 (2013). 
35. Jeong, J. et al. Ultrasensitive detection of hazardous reactive oxygen species using flexible organic transistors with polyphenol-embedded conjugated polymer sensing layers. J. Hazard Mater. 355, 17-24 (2018).

36. Attri, P. et al. Generation mechanism of hydroxyl radical species and its lifetime prediction during the plasma-initiated ultraviolet (UV) photolysis. Sci. Rep. 5, 9332 (2015).

37. Zang, L. Y. \& Misra, H. P. EPR kinetic studies of superoxide radicals generated during the autoxidation of l-methyl-4-phenyl-2,3dihydropyridiniuma, a bioactivated intermediate of parkinsonian-inducing neurotoxin l-methyl-4-phenyl-1,2,3,6-tetrahydropyridin. J. Biol. Chem. 267, 23601-23608 (1992).

38. Taubert, D. et al. Reaction rate constants of superoxide scavenging by plant antioxidants. Free Radic. Biol. Med. 35, 1599-1607 (2003).

39. Quesada, A. R., Byrnes, R. W., Krezoski, S. O. \& Petering, D. H. Direct reaction of $\mathrm{H} 2 \mathrm{O} 2$ with sulfhydryl groups in HL-60 cells: zinc-metallothionein and other sites. Arch. Biochem. Biophys. 334, 241-250 (1996).

40. Chen, T.-H., Nieh, C.-C., Shih, Y.-C., Ke, C.-Y. \& Tseng, W.-L. Hydroxyl radical-induced etching of glutathione-capped gold nanoparticles to oligomeric AuI-thiolate complexes. RSC Adv. 5, 45158-45164 (2015).

41. Shiang, Y.-C., Huang, C.-C. \& Chang, H.-T. Gold nanodot-based luminescent sensor for the detection of hydrogen peroxide and glucose. Chem. Commun. 23, 3437-3439 (2009).

42. Kilian, K. \& Pyrzynska, K. Spectrophotometric study of $\mathrm{Cd}(\mathrm{II}), \mathrm{Pb}(\mathrm{II}), \mathrm{Hg}(\mathrm{II})$ and $\mathrm{Zn}(\mathrm{II})$ complexes with 5,10,15,20-tetrakis(4-carboxylphenyl)porphyrin. Talanta 60, 669-678 (2003).

43. Ishii, H., Satoh, K., Satoh, Y. \& Koh, H. Spectrophotometric and analogue derivative spectrophotometric determination of ultramicro amounts of cadmium with cationic porphyrins. Talanta 29, 545-550 (1982).

44. $\mathrm{Fu}, \mathrm{W}$. et al. Graphene transistors are insensitive to $\mathrm{pH}$ changes in solution. Nano Lett. 11, 3597-3600 (2011).

45. Fu, W. et al. High mobility graphene ion-sensitive field-effect transistors by noncovalent functionalization. Nanoscale 5, 12104-12110 (2013).

46. Fu, W., Jiang, L., van Geest, E. P., Lima, L. M. C. \& Schneider, G. F. Sensing at the surface of graphene field-effect transistors. Adv. Mater. 29, 1603610 (2017).

47. Wen, Y. G., Liu, Y. Q., Guo, Y. L., Yu, G. \& Hu, W. P. Experimental techniques for the fabrication and characterization of organic thin films for field-effect transistors. Chem. Rev. 111, 3358-3406 (2011).

48. Buth, F., Kumar, D., Stutzmann, M. \& Garrido, J. A. Electrolyte-gated organic field-effect transistors for sensing applications. Appl. Phys. Lett. 98, 153302 (2011).

49. Thomas, D. D., Liu, X., Kantrow, S. P. \& Lancaster, J. R. Jr. The biological lifetime of nitric oxide: implications for the perivascular dynamics of $\mathrm{NO}$ and $\mathrm{O}_{2}$. Proc. Natl Acad. Sci. USA 98, 355-360 (2001).

50. Dikalov, S., Khramtsov, V. \& Zimmer, G. Determination of rate constants of the reactions of thiols with superoxide radical by electron paramagnetic resonance: critical remarks on spectrophotometric approaches. Arch. Biochem. Biophys. 326, 207-218 (1996).

51. Stern, E. et al. Importance of the debye screening length on nanowire field effect transistor sensors. Nano Lett. 7, 3405-3409 (2007).

52. Fowler, J. D. et al. Practical chemical sensors from chemically derived graphene. ACS Nano 3, 301-306 (2009).

53. Ohno, Y., Maehashi, K., Yamashiro, Y. \& Matsumoto, K. Electrolyte-gated graphene field-effect transistors for detecting $\mathrm{pH}$ and protein adsorption. Nano Lett. 9, 3318-3322 (2009).
54. Hao, Z. et al. Real-time monitoring of insulin using a graphene field-effect transistor aptameric nanosensor. ACS Appl. Mater. Interfaces 9, 27504-27511 (2017).

55. Weinstein, J. \& Bielski, B. H. J. Kinetics of the interaction of $\mathrm{HO}_{2}$ and $\bullet^{-}{ }^{-}$ with hydrogen peroxide the haber-weiss reaction. J. Am. Chem. Soc. 101, 58-62 (1979).

56. Xing, M. et al. Metal sulfides as excellent co-catalysts for $\mathrm{H} 2 \mathrm{O} 2$ decomposition in advanced oxidation processes. Chem 4, 1359-1372 (2018).

\section{Acknowledgements}

This work was supported by the National Natural Science Foundation of China (51773041, 61890940, 21603038, 21544001), Shanghai Committee of Science and Technology in China (18ZR1404900), the Strategic Priority Research Program of the Chinese Academy of Sciences (No. XDB30000000), National Program for Thousand Young Talents of China, and Fudan University.

\section{Author contributions}

D.W. designed the research. D.W. and Y.L. supervised the project. Z.W. and K.Y. prepared the sample and did SEM, TEM, and XPS. K.Y., Z.W., L.Y. and X.C. fabricated the device. Z.W. and X.C. measured the device. K.Y., Q.L. and H.C. measured the device with Hela cells. D.W., Z.W. and K.Y. prepared the manuscript. All authors commented on the manuscript.

\section{Additional information}

Supplementary Information accompanies this paper at https://doi.org/10.1038/s41467019-09573-4.

Competing interests: The authors declare no competing interests.

Reprints and permission information is available online at http://npg.nature.com/ reprintsandpermissions/

Journal peer review information: Nature Communications thanks Wangyang Fu and the other anonymous reviewer(s) for their contribution to the peer review of this work.

Publisher's note: Springer Nature remains neutral with regard to jurisdictional claims in published maps and institutional affiliations.

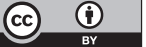

Open Access This article is licensed under a Creative Commons Attribution 4.0 International License, which permits use, sharing, adaptation, distribution and reproduction in any medium or format, as long as you give appropriate credit to the original author(s) and the source, provide a link to the Creative Commons license, and indicate if changes were made. The images or other third party material in this article are included in the article's Creative Commons license, unless indicated otherwise in a credit line to the material. If material is not included in the article's Creative Commons license and your intended use is not permitted by statutory regulation or exceeds the permitted use, you will need to obtain permission directly from the copyright holder. To view a copy of this license, visit http://creativecommons.org/ licenses/by/4.0/

() The Author(s) 2019 